\title{
El Nicaragüense y los enlaces transnacionales de los filibusteros
}

Recepción: 25-05-2016/ Aceptación: 25-10-2016

Andreas Beer

a.beer@live.com

\section{Resumen}

Basado en el análisis del periódico decimonónico El Nicaragüense, este artículo argumenta que el fenómeno de los filibusteros en Nicaragua en los años 1855-1857 sólo puede entenderse si salimos de los límites nacionales y miramos hacia procesos, productos y actores transnacionales. El texto analiza como esa publicación bilingüe editada por los filibusteros trasladó un concepto de periodismo estadounidense al istmo centroamericano y chocó con las ideas nicaragüenses al respecto, simbolizando sin embargo, una idea de progreso para algunos adherentes al liberalismo en tierras nicaragüenses. Explora el éxito propagandístico del diario, limitado su circulación a Estados Unidos; no obstante, su impacto en ese país fue enorme. El ensayo también discute la influencia de los cubanos en la tropa de Walker y concluye que estos jugaron un papel clave en los procesos de traducción lingüística y cultural entre anglosajones y nicaragüenses.

Palabras claves: Guerra Nacional; El Nicaragüense; prensa estadounidense; prensa nicaragüense; historia transnacional, participación cubana

\section{Abstract}

Studying El Nicaragüense filibuster's publication, a paper argue that the filibuster's phenomena in Nicaragua (1855-1857) can be understood if we have a look towards process, products and transnational actors. The paper analyzes how the bilingual newspaper transfers an American journalism concept to the ism that collided Nicaraguan ideas; however meant progress for those related to liberalism in Nicaragua. The paper explores the newspaper propagandistic success that despite of having limited circumscription to the United State, had an enormous impact. This essay also discuss Cubans influence of Cubans in Walker's troop, and concludes that they played an important communication role in cultural and linguistic translation between Nicaraguan and Anglo - Saxons.

Keywords: National war; El Nicaragüense, Nicaragua, XIX Century, American Press; Nicaraguan Press; William Walker, Patricio Rivas, Francisco Argüello Estrada, Transnational History.

\section{Introducción}

Como todos los años, durante las fiestas patrias en septiembre se lleva a cabo la conmemoración de la Batalla de San Jacinto. El evento evoca la primera victoria de tropas nicaragüenses contra los filibusteros en la llamada Guerra Nacional. La asociación entre la conmemoración anti-filibustera y la celebración de la independencia nacional subraya la importancia de este conjunto de eventos, para la identidad colectiva del moderno estado nicaragüense. En estas celebraciones se articula una idea del estado nacional que incorpora artefactos de la conquista (como el Güegüense) con narrativas acerca de la gesta mítica de Andrés Castro, al protagonismo literario de Rubén Darío, Sandino, vinculado todo a la revolución sandinista. 
De esa manera, la lucha contra los filibusteros forma parte de - y algunos argumentan que reemplaza a - la narración colectiva de la independencia nacional: la independencia de Nicaragua fue un acto protocolario, formal, expresado en el territorio nicaragüense, por sublevaciones locales (como antecedentes, los registrados en León y Granada), cuyo centro de rebelión estaba en otros países. Durante el siglo XIX los dirigentes liberales de la nación decidieron construir una memoria colectiva basada en una lucha exitosa contra los filibusteros como invasores extranjeros. Bajo este punto de vista, los sucesos de la lucha anti-filibustera se han mirado por décadas como un hecho exclusivamente nicaragüense, minimizando las contribuciones de otras naciones centroamericanas (Costa Rica, en primer lugar, Guatemala y Honduras, entre otros).

De igual manera, se ha evitado discutir acerca del carácter multinacional de la tropa filibustera o las colaboraciones de figuras nicaragüenses con Walker, inicialmente invitado (contratado) a Nicaragua y celebrado como "el salvador", dado que ayudaría a terminar la guerra civil entre los legitimistas y liberales. Cuando salimos del rasgo de la "Gran Historia", o sea de la historia de batallas y de gestas heroicas personalizadas y nos enfocamos en la historia cotidiana, se puede observar un panorama mucho más complejo y multipolar.

Este artículo analiza el periódico El Nicaragüense, publicado por los filibusteros en Granada a partir de octubre de 1855 hasta noviembre del siguiente año, cuando las huestes invasoras abandonaron su base de operaciones principales en la ciudad de Granada. Diario poco conocido hoy día, fue editado en dos idiomas - inglés y español - y en dos caras: una dirigida hacia Estados Unidos como instrumento de propaganda colonialista, y la otra como diario oficial de una administración de gobierno encabezada por Patricio Rivas. Unidos en una publicación, estas dos caras generaron un punto de vista "bifocal": El Nicaragüense emergió como un artefacto transnacional, ubicado entre la esfera nacional de Nicaragua y Estados Unidos y también como medio, entre los paradigmas centroamericanos $\mathrm{y}$ norteamericanos del periodismo.

El estudio de este periódico, pretende contribuir al esfuerzo de historiadores e historiadoras de encontrar nuevas claves de interpretación a los acontecimientos de la Guerra Nacional desde fuera de los límites nacionales. En este sentido, se comienza con una descripción de la producción del diario filibustero dentro del contexto de los años 1855 - 1856 discutiéndose luego, su impacto nacional e internacional. La mirada nacional y su vínculo con el filibusterismo alumbran el carácter internacional de la tropa de Walker, enfocado en sus integrantes cubanos. Después, se discute la posición de El nicaragüense en la historia del periodismo de Nicaragua. La conclusión del trabajo intenta abrir caminos para futuras investigaciones a partir de algunas preguntas y desiderata.

\section{El periodismo nicaragüense en los años 1850}

Cuando William Walker y sus hombres desembarcaron en puerto de El Realejo y se incorporaron al ejército liberal, se hizo notar que al menos algunos de los estadounidenses tenían una visión de cambio político-social para Nicaragua, que iba más allá de quedarse
[Walker quiso] apropiarse de las fincas de los que consideraba enemigos, para adjudicarlas a los americanos; de enajenar a los extranjeros quinientos mil acres de las mejores tierras de la República, al infame precio de cuatro reales el acre, para invertir su producto en fuerzas opresoras del país, expresando el designio de emplear estos recursos en verificar reformas políticas y religiosas (Rivas, 1856). 
como colonizadores. La cúpula visionó el país como un nuevo estado federal de Estados Unidos, gobernado por el mismo código legal y con una organización social similar a la conocida en el norte. Consecuentemente, y con el apoyo inicial de los liberales, empujaron diferentes proyectos para lograr esta similitud: invitaron a ciudadanos anglosajones estadounidenses a venir, no sólo a luchar con ellos, sino a quedarse como campesinos o artesanos. Ellos intentaron introducir diferentes leyes de Estados Unidos como la promulgación del inglés como idioma oficial o cambiando el régimen y la titulación de propiedad de la tierra.

El programa de "americanization" de junio de 1856 fue uno de los puntos claves para la ruptura entre la administración de Patricio Rivas y los filibusteros dirigidos por Walker. Los cambios en el régimen legal, supuso un enorme peligro al poder político y económico de la élite de hacendados. Como lamentó el mismo Rivas después de huir de Granada:

Desde el inicio de su estancia, Walker y su círculo trabajaron para lograr estas metas, y como adherentes de la idea de la misión civilizadora basada en ideal(es) de la Ilustración, estaban convencidos que la fundación de un periódico formaba parte de la supuesta reforma social. Como bien nos recuerda Brady Harrison en su estudio donde delinea las intersecciones entre el mundo literario-periodista, con lo que llama carácter imperial de la época del Manifest Destiny estadounidense: "un aspecto clave del carácter imperial: su voz, su habilidad para persuadir a otros y a través de su poder lingüístico cambiar el mundo" (Harrison, 2004, p. 29). ${ }^{1}$

Este poder lingüístico sirve "como una da las armas más importantes" en el arsenal de los llamados "maestros de elocuencia" (Harrison, 2004, p. 35). Aunque Harrison habla de manera clara en superlativos y se enfoca en los líderes intelectuales del imperialismo, su análisis del nexo entre poder militar y capacidades de retórica, son recurrentes con las ideas de Max Weber sobre personalidades carismáticas y pueden ser aplicable para la descripción de Walker y otros jefes filibusteros (De igual manera, para imperialistas en general, como nos recuerda David Spurr).

Siempre en esta línea, Benedict Anderson ha subrayado la importancia de novelas y periódicos para la configuración narrativa y ficticia del estado nacional (véase Anderson, 2003). De manera instintiva los filibusteros seguían estos pasos de construcción nacional porque considerándolos similares a los dados por los independentistas de los años veinte del siglo XIX, como Simón Bolívar o José de San Martín.

También hay que tener en cuenta la importancia del primer informativo que hacía referencia a la situación de Nicaragua en el contexto de la guerra civil. Precisamente el periodismo tiene un gran poder creativo en períodos donde reinan los rumores y la incertidumbre. Los filibusteros intentaron posicionarse como las únicas voces fiables de habla inglesa en el territorio nicaragüense. A partir de estos aspectos, es lógico suponer que Walker ordenara la apertura de un diario lo más pronto posible. Esta se presentó cuando los filibusteros entraron a la ciudad de Granada en octubre de 1855 y encontraron únicamente restos de la prensa local.

En esa época la esfera de periodismo en Nicaragua era muy limitada. La pobreza económica y la concentración de poder político-social en manos de unas pocas familias de hacendados, significó que la gran mayoría de la población se mantuviera en el analfabetismo. Dentro de esa mayoría, debe de pensarse de manera especial, en el género. En una sociedad patriarcal como la nicaragüense de este período en estudio, 
las mujeres no eran admitidas dentro del incipiente sistema educativo, más allá de esfuerzos individuales de aprendizaje básico. No existen datos estadísticos, pero en su importante obra sobre el periodismo en Nicaragua, Miguel Ayerdis estima que hasta la así designada década liberal de los años 70 del siglo XIX, la tasa del alfabetismo rondaba el $10 \%$ a nivel nacional (Ayerdis, 2005, p. 16). Las publicaciones que existían entonces fueron dirigidas a un círculo muy limitado de personas que muchas veces obtuvieron un rol multivocal en la sociedad nicaragüense, como políticos y patrones hacendados, pero también como escritores, periodistas y "gente de letra" en general. En estos debe de incluirse a Francisco Castellón, los ministros liberales Buenaventura Selva, Hermenegildo Zepeda y Francisco Díaz Zapata. Por el lado conservador, a Mateo Mayorga, Sebastián Salinas o Fruto Chamorro (presidente y editor de El Mentor Nicaragüense).

Las publicaciones existentes en la década de los 40 y 50 estaban ligadas, en su mayoría, a los dos centros intelectuales del país: León (el bastión liberal) y Granada (ciudad sede del conservatismo). Sólo estos dos puntos focales contaban con prensas, vinculadas a las dos estructuras políticas dominantes. Eran periódicos de una a cuatro páginas, cuya circulación se daba de manera preferencial entre estudiantes y miembros de las familias que dirigían la política del país.

Estas publicaciones eran irregulares en su producción y circulación (debido al hecho de que por lo general eran producto de una sola persona que figuraba como escritor y redactor). Muchas veces sus contenidos respondían a ataques o rumores escritos en las publicaciones enemigas. La esfera del periodismo en ese entonces, reflejaba el modelo de conversación académica escrita en los folios letrados, descrito por Jürgen Habermas como precursor de la esfera pública burguesa (Habermas, 2010). No existía un mercado para publicaciones periódicas, como sí existía en Europa, Estados Unidos y algunos países de América del Sur (véase Guerra \& Lempérière, 1998).

\section{El Nicaragüense y sus orígenes en la prensa estadounidense}

En el anterior apartado se hizo una breve descripción del panorama político y cultural en el que intervinieron los filibusteros. Algunos de estos aventureros tenían experiencia en el periodismo: William Walker se había desempeñado como redactor del New Orleans Daily Crescent (donde reemplazó al poeta estadounidense Walt Whitman); Joseph Malè, George Cook, John Tabor y Francisco Agüero Estrada, sirvieron como editores de El Nicaraguense en varias ediciones. Otros columnistas regulares, como J.T. Cady y J.W. de Frewer, también tenían alguna experiencia en el mundo de la prensa. Este grupo de filibusteros tenía una visión del periodismo muy diferente a la del modelo nicaragüense, orientándose a la realidad estadounidense dónde la prensa ya jugaba un papel protagónico en la vida cotidiana. Estados Unidos había experimentado un crecimiento de tasa de alfabetismo casi el 50 por ciento de la población desde la década del 40. Los almanaques, panfletos y de manera especial los diarios se convirtieron en la lectura preferida de la población. Los libros por su consto alto, seguían fuera del alcance de la clase obrera y campesina (véase Rodríguez Díaz, 1997; Zboray, 1993, 1997). Los años 50 vieron un hábito de lectura "promiscua", mundana (Zboray, 1997, p. 195), en otras palabras, era una práctica de consumo de textos, alejadas de obras canónicas como la biblia. Las fuentes eran variadas, en su mayoría publicaciones periódicas, orientadas a la comprensión del mundo social y político de la época.

Mientras tanto, elementos orales como las reuniones de ciudadanos ("town hall meetings"), sermones religiosos o los discursos públicos persistieron. Los esclavos negros y otros grupos "minoritarios", fueron excluidos de esta tendencia cultural de 
consumo de publicaciones periódicas. Puede decirse que desde finales de la década de los 40 el periodismo moderno en sus diversos género había llegado a Estados Unidos (véase Brodhead, 1994).

Existieronenla pujantenaciónnorteamericana de la época, una variedad de periódicos a nivel local, muchos de estos afiliados a partidos o tendencias políticas, pero con una creciente orientación independiente y con una visión hacia lo nacional. Se ofrecieron publicaciones diarias, semanales o mensuales, enfocados en la economía, otros eran satíricos o también estaban los así llamados "story papers", publicaciones que contaban historietas de sucesos militares, de expediciones geográficas o simplemente de aventuras. Estos últimos, usaban dibujos profesionales y el estilo de reportaje era una especie de híbrido entre las revistas literarias de contenido ficticio y el periodismo de actualidad, dado que en muchas ocasiones los escritores no había participado de manera 14 directa en los sucesos (Streeby, 2002, p. 25; Zboray, 1993, p. 120).

Esa explosión en la industria de las publicaciones - apoyado por innovaciones técnicas como imprentas más poderosas, una distribución más rápida merced de la amplificación de la red de barcos y trenes de vapor o algo tan sencillo como gafas de bajo precio y la disponibilidad de luz eléctrica para leer después del trabajo en la tarde - resultó en una competencia feroz para atraer a lectores. Como parece ser una constante antropológica, los escándalos y hechos violentos atraen la atención humana, generando competencia, estableciendo la primera fase de la prensa amarilla en Estados Unidos.

Una de las características de la prensa estadounidense de esa época es que podía encontrarse una mezcla vivaz de noticias amarillas, chistes (muchas veces racistas), reportajes serios, historias copiadas de otros diarios - muchas veces de Francia o Inglaterra
- noticias tendenciosas, noticieros locales y editoriales, artículos de opinión. Todo esto compartido en el mismo medio y en muchas ocasiones dentro de la misma página.

Este tipo de periódicos fue el que William Walker y sus hombres conocieron, consumieron y practicaron en ocasiones, en sus lugares de origen. Será esta concepción de periodismo la que trataron de aplicar en Nicaragua con el periódico que fundaron. Walker, en su calidad de comandante-enjefe estaba decidido a convertir la iniciativa periodística en algo exitoso, y aunque necesitaba que todos sus hombres estuvieran dedicados a la lucha armada que libraba al interior del país centroamericano, destinó a dos de ellos como editores de tiempo completo. Esos editores fueron -como se mencionó arriba-- Malè y Cook, este último, reemplazado por Charles Cutler, y al morir asumiría el cargo Tabor.

Cuando Tabor muere - riesgo común en la profesión aventurera de filibustero finalmente Owen Duffy toma su lugar al lado de Joseph Malè, el editor más importante de la publicación. La sección en español contó con un solo editor, el ya mencionado Francisco Agüero Estrada. Aparte de los editores, Walker designó cuatro soldados más como tipógrafos (Bolaños Geyer, 1998, p. 309-b).

Walker supervisaba la redacción con ojo de lince, evidenciando la importancia que le daba el jefe mercenario, al periódico. Esto también le motivaría a colaborar en algunas ocasiones con artículos. La imprenta donde se editaba el periódico la instaló en el mismo edificio de su comandancia con el fin de tener cerca el proyecto editorial y controlara todo lo que se editara (Bolaños Geyer, 1998, p. xiii).

Al inicio el diario El Nicaragüense evidenció carencias en recursos como papel, materiales a publicar e incluso cuido en la redacción: eran dos páginas. El primero número 
fechado el 20 de octubre de 1855 traía únicamente un corto texto en español ("A nuestros amigos hijos del país") donde se anunciaba para los números subsiguientes, una parte en idioma español más extensa. A excepción de este escrito, los restantes materiales que traía ese número, estaban en inglés. Se observan deficiencias ortográficas y tipográficas, principalmente en su título. Se puede especular que estos problemas de edición se debieran a la falta de personal hispano parlante competente, pero había sus colaboradores que eran nativos de la lengua española, y como se puede observar en los ejemplares existentes, El Nicaragüense se quedó sin la diéresis en su título hasta su liquidación.

Pronto el diario creció en extensión y páginas llegando a tener entre cuatro y ocho páginas en cada número que apareció. Los filibusteros llegaron a una frecuencia de publicación muy rigurosa y regular: El Nicaragüense salía al público cada sábado, excepto en tres ocasiones cuando la circunstancia del conflicto armado le exigió a los filibusteros, disponer todas sus fuerzas a operaciones militares.

En comparación con los diarios nicaragüenses que dependían casi siempre de una sola persona, en términos de redacción y edición, afectando su frecuencia de salida, el número del personal designado por Walker para el trabajo directo en el periódico, y aquellos filibusteros colaboradores regulares, redondearon una buena base de personas dedicadas a esta empresa. Eso explica la enorme producción publicitaria que se observa en los ejemplares editados, con más de 4.000 artículos escritos por los redactores y colaboradores, 450 documentos oficiales reproducidos y miles de noticias copiadas de otras publicaciones (Bolaños Geyer, 1998, p. xviii).

La sección en español del periódico comenzó a editarse a partir del segundo número. En el cuarto número, se observa un equilibrio en páginas entre la edición inglesa y la española (cada una de ellas abarcaba dos páginas. Pese a ello, el enfoque de la publicación filibustera siempre estuvo un sesgo propagandístico que priorizaba al público de Estados Unidos. A pesar del espacio que le destinaban al público de habla hispana, siempre le dieron poca importancia a este segmento cultural.

Al fungir como órgano oficial, la mayor parte del material era repetido en ediciones subsiguientes. La misma necesidad de legitimidad y de hacer que el público conociera las medidas del gobierno, les impulsaba a mantener por varias ediciones, proclamas, leyes $\mathrm{u}$ otra medida emitidas por el Presidente Patricio Rivas o alguno de sus ministros.

El hecho que la cabecera de El Nicaragüense les diera crédito a los redactores angloparlantes, no así a los redactores/editores en idioma español, subraya la predominancia del enfoque pro norteamericano y anglosajón del diario bilingüe. Es de notar que el periódico sólo reveló a Francisco Agüero Estrada como su redactor en mayo de 1856, después de más que veinte números en los que aparecen artículos en español. El colmo de la negligencia, el corto texto en inglés donde se informa del redactor, aparece mal escrito su apellido y cambiando el nombre, “José" por Francisco (Tabor, 1856b).

El filibustero Francisco Agüero Estrada era cubano, hermano de Joaquín de Agüero y Agüero, uno de los principales actores de la primera ola del independentismo en la isla caribeña. Ambos provenían de una rica familia de hacendados en Camagüey. Después de la muerte de su padre, Joaquín heredó no sólo las plantaciones sino también la mano de obra esclava de la familia. En un gesto influenciado por las ideas de la Ilustración, Joaquín decidió liberarlos. Este fue un primer paso hacia su radicalización en sus aspiraciones independentistas. Empezó a imprimir panfletos anti-coloniales, presidir la Sociedad Liberadora de Camagüey llegando a reunir grupos de simpatizantes y tomar 
armas contra la administración de la corona española en la isla.

Durante el año de 1851, su hermano Francisco le apoyó en varias acciones de lucha y cuando la persecución colonial se intensificó al siguiente año ambos huyeron a Estados Unidos (Luis-Brown, 2009, p. 452). Joaquín regresó a Cuba de inmediato a seguir luchando por la independencia, siendo capturado, torturado y ejecutado por las autoridades, mientras Francisco se quedó en Nueva York instalándose en los círculos cubanos de la metrópoli de la costa este donde ejerció como periodista y poeta.

Los círculos o clubes políticos cubanos existieron desde los años cuarenta, se auto-denominaban "libertadores", "revolucionarios" o (en algunos casos) "filibusteros" (por ejemplo, publicaron un diario llamado El Filibustero) y fueron en su gran mayoría independentistas, buscaban la liberación de la isla natal del yugo español (Lazo, 2005). El más famoso de ellos, sin duda, era el venezolano Narciso López, quien organizó varias expediciones hacía la isla y murió en su último intento en 1851. Existían una diversidad de opiniones de cómo realizar la independencia, para este artículo, basta destacar la brecha de discusión más importante: la interrogante acerca de la lucha para una Cuba libre formando parte de Estado Unidos (incorporado como estado federal a la unión) o como nación independiente.

En su mayoría, los cubanos exiliados en la costa este de Estados Unidos fueron liberales y el modelo unionista, popular a nivel internacional, desde el punto de vista republicano y económico, era una razón de gran valor para que abogaran por la anexión a este país del norte. Esta idea emocionó a una partes importantes de la comunidad política estadounidense, como a John A. Quitman, gobernador de Mississippi, quien apoyaría en términos financiero o en algunos casos material y con voluntarios esta causa
(May, 1985).

Como la expansión territorial en los años 40 y principios de los 50 del siglo XIX fue una opción viable para el movimiento cultural y político "Young America" y de la administración de los presidentes Millard Fillmore y Franklin Pierce, los cubanos radicados en Estados Unidos simpatizaron con esta visión y deseaban unirse con los norteamericanos para liberar a la isla y formar parte de esta último país. Como en Cuba aún existía la esclavitud, la otra gran discusión giraba alrededor del estatus de ese régimen inhumano: si los independentistas optasen por la incorporación a Estados Unidos, la prolongación de la esclavitud hubiera significado un voto más para el sur esclavista en el Senado estadounidense. Ante esta disyuntiva, cubanos que luchaban por la abolición buscaría apoyar a las fuerzas antiesclavista.

En medio de esta mezcla de posiciones y ambiciones aparece Francisco Agüero Estrada posicionándose pronto a favor de una independencia total de Cuba, oponiéndose a la anexión de la isla a Estados Unidos. Durante el tiempo que trabajó en los periódicos El Pueblo y El Mulato, su voz fue una de las más fervientes en criticar la junta de los cubanos que favorecían la anexión. Con artículos como "Errores de la revolución cubana," El Pueblo llamó la atención sobre las inconsistencias de las posiciones favorables a la anexión. De esta manera, se generaría una matriz de opinión diferente que en los años de 1854-1855 inclinaría la opinión de los círculos o clubes de exiliados cubanos a favor de la independencia total (Lazo, 2005, pp. 94-95).

Con este trasfondo crítico a las posiciones expansionistas de Estados Unidos, resulta inexplicable el apoyo de Agüero Estrada a la causa filibustera, dejando Nueva York en 1855 y viajando a Nicaragua e incorporándose a las huestes aventureras de Walker. Decenas de cubanos se enrolaron al 
grupo de filibusteros en Nicaragua, algunos como Domingo de Goicuría, --considerado héroe de la independencia cubana--, apoyaba la causa desde una década antes, incluso acompañó las expediciones de Narciso López; otros se enrolaron invitados por Walker, o por su propia iniciativa.

Todos estos antillanos coincidían en la convicción que Nicaragua bajo el control de los liberales nicaragüenses o de fuerzas provenientes de Estados Unidos, la liberación de Cuba sería más fácil. Al parecer Walker les prometió apoyo para la causa cubana, al menos a Goicuría. La decepción vendría pronto. Cuando Walker tomó el poder real (Patricia Rivas ejercía un poder nominal) y con el programa de "Americanization" en marcha, donde establecía la re-introducción de la esclavitud en tierras nicaragüenses, los cubanos abandonaron a los filibusteros (El Nicaragüense del 16 de agosto de 1856, después del éxodo, todavía menciona a 32 cubanos en las filas filibusteras). Su líder intelectual, Goicuría, dimitió aunque Walker le había hecho embajador para Inglaterra y Francia; y Francisco Agüero Estrada dejó el cargo de redactor de El Nicaragüense el 14 de mayo de 1856, citando razones de salud (Agüero Estrada, 1856b).

Durante el período en que Agüero Estrada y resto de cubanos estuvieron en las filas filibusteras, fueron claves en los éxitos iniciales de Walker y sus huestes. Ellos fueron los vínculos entre la sociedad católica e hispanoparlante centroamericana y los anglosajones del Norte. La comunicación entre los filibusteros y la cúpula del partido liberal, se facilitó debido, no sólo al aporte de traducción hecha por como Charles Thomas, comerciante estadounidense radicado en Nicaragua desde mucho tiempo atrás, sino por el grupo de cubanos de base cultural hispana caribeña. Para Michel Gobat, los cubanos eran los "intermediadores más importantes que definieron las relaciones entre Walker y el pueblo nicaragüense [...] porque los cubanos compartían la creencia de muchos nicaragüenses de que la mejor manera de desarrollar su país era a través de su 'americanización'”' (Gobat, 2006, p. 80).

\section{El Nicaragüense como medio transnacional entre Estados Unidos y Nicaragua}

El medio más importante para la difusión de las ideas liberales lo constituyó el órgano oficial de los filibusteros, el periódico El Nicaragüense. A través de traducciones de editoriales escritos por Walker, Agüero Estrada intentó familiarizar a los lectores nicaragüenses con los planes y proyectos de los filibusteros aprovechando cada ocasión para vincular la lucha en Nicaragua con la liberación de Cuba. En el editorial "Los Americanos y los Centro-Americanos" subrayó que los legitimistas (conservadores) eran los mismos "desde Cuba hacia California" y por eso los filibusteros, aunque tal vez extraño en varios aspectos, eran hombres de confiar en una lucha compartida (Agüero Estrada, 1856a).

Como Agüero Estrada era el único redactor de habla hispana en la redacción del periódico, las traducciones fueron escasas y en varias ocasiones inoportunas. Cuando los filibusteros fantasearon sobre el gran apoyo que supuestamente tenían en la sociedad nicaragüense o cuando los artículos hacían énfasis en la superioridad de la raza anglosajona, Agüero Estrada no los traducía. Las listas de oficiales de guardia, informaciones sobre procesos de sanción en el ejército filibustero o las noticias de periódicos de California no merecieron tampoco la traducción de Agüero Estrada. En vísperas de la ruptura entre Walker y Rivas, esta tendencia se acentuó: informaciones claves se quedaron en inglés sin traducir.

La edición número 33 de periódico es particularmente interesante en términos de las traducciones del material a publicar: Después de la fuga de Rivas, la sección en 
inglés publicó varios pronunciamientos de Walker, uno de ellos dirigido a sus tropas donde el jefe filibustero les motivaba a continuar luchando por su "país adoptivo". La sección en español no menciona la palabra fuga en conexión con Rivas y no traduce los pronunciamientos, pero publica una nota escrita por Fermín Ferrer donde explica, en su calidad de "ciudadano", las razones por las que se vio obligado a asumir el gobierno en sustitución de Patricio Rivas.

Agüero Estrada llenó las páginas de la "Sección español" con noticias sobre América Latina, extraídas todas ellas, de periódicos que llegaban del extranjero por medio de la línea de vapores que regularmente hacían la ruta Chile-México, pasando por Perú. La mayoría de estas publicaciones que llegaban de esos países eran órganos oficiales. Patricio Rivas, anterior a la ruptura con los filibusteros, consideró a El Nicaragüense órgano oficial de su gobierno, por esa razón la sección en español reproducía correspondencia oficialista y proclamas, contrastando con la sección en inglés que reproducía temas o sucesos de Estados Unidos.

La sección en inglés contó con reportajes (reales o ficticios) de los miembros del ejército filibustero relacionados con Nicaragua. Contenía anuncios publicitarios (pocos y repetitivos de albergues y vapores controlados por extranjeros), elementos gráficos, artículos de opinión, correspondencia pública, desde y hacia EE UU, rumores sociales, chistes, extractos de libros de autores de habla inglesa que hacían referencia a Centroamérica, relatos sobre la (supuesta) vida cotidiana en Granada e invitaciones a eventos sociales.

Esa estructura de contenido del periódico se enmarcaba dentro de un esfuerzo publicitario para dar una imagen de normalidad del país en el exterior que nunca existió durante la permanencia de los filibusteros. La sección en inglés era el típico ejemplo de un periódico de mediado del siglo XIX en Estados
Unidos o Europa pero no de Nicaragua. La sección en español, reproducía las prácticas y el perfil que la mayoría de los periódicos centroamericanos tenían en esa época: panfletarios, llenos de noticias oficialistas.

Una mirada a la composición, el enfoque y las fuentes elegidas, se puede señalar que el experimento de El Nicaragüense de combinar dos secciones en un periódico, en dos idiomas distintos y contenidos diferentes para dos grupos de lectores culturalmente opuestos en su raíz histórica - Estados Unidos y Centroamérica - hizo que no prosperara como proyecto editorial. Durante toda su existencia, este periódico filibustero fue en la práctica dos periódicos impresos en una misma edición, reflejando dos contextos sociales, lingüísticos e históricos diferentes.

Es probable encontrar conexiones temáticas o de interés de acuerdo al objetivo que perseguía el periódico. No obstante, la realidad era que los filibusteros lo producían pensando más en el público norteamericano que el nicaragüense. El título es sugerente, El Nicaraguense, pretendiendo con esto, establecer una identificación con el pueblo, opiniones y formas de vida, pero el descuido ortográfico en el título evidencia el menosprecio que los filibusteros sentían hacia los centroamericanos.

\section{Sería demasiado fácil calificar El Nicaragüense como una publicación estadounidense producida en Centroamérica. También es importante destacar que su pretendida doble mirada lo sitúan en un ámbito transnacional, hemisférico de una idea civilizadora liberal que motivó a cubanos, lo mismo que a estadounidenses o nicaragüenses; a católicos como a luteranos.}

Es sintomático que este periódico filibustero difícil de clasificar, sea considerado un diario estadounidense por muchos historiadores, no formando parte de la historia del periodismo nicaragüense. Pese a ello, es anecdótico el hecho que el archivo más completo de esta 
publicación y de documento histórico sobre el tema hoy día, se encuentra Nicaragua gracias al esfuerzo y dedicación del historiador Alejandro Bolaños Geyer.

Bolaños Geyer, médico de profesión, al triunfo de la revolución sandinista en 1979 emigró a Estados Unidos y durante el tiempo que vivió en este país, desarrolló un enorme interés por los filibusteros emprendiendo una búsqueda frenética de documentos, en ese entonces, diseminados en diversos archivos de Norteamérica. Durante ese tiempo coleccionó y publicó una serie de documentos. Al fallecer legó este acerbo documental a la Universidad Centroamericana de Managua.

\section{El impacto propagandístico de EI Nicaragüense}

El plan original de los filibusteros era que El Nicaragüense jugara su papel propagandístico en Centroamérica al igual que en Estados Unidos, la realidad fue otra, el éxito de esta publicación se limitó a este último país, donde tuvo una buena recepción. La prensa estadounidense anhelaba noticias del istmo y de los supuestos patriotas y El Nicaragüense era el único medio que enviaba información directamente desde Nicaragua y en inglés.

Muchos periódicos, incluyendo el New-York Daily News, copiaron artículos del órgano filibustero en sus columnas sin mencionar su cuestionable origen, generando así una enorme plataforma para la versión partidista de los acontecimientos en Centroamérica. En una época donde los estándares profesionales de los periodistas apenas se estaban configurando, y en un clima de simpatía por las acciones expansionistas de Walker y los suyos, no sorprende que los diarios estadounidenses en su mayoría, aceptaran artículos tendenciosos sin un mínimo de control crítico.
Los filibusteros aprovecharon el apoyo de ciertos reporteros simpatizantes de su causa y que llegaron al país, así como de capitanes de barcos y pasajeros de los vapores que hacían la ruta ístmica para llevarle ejemplares de El Nicaragüense a Estados Unidos. Esta estrategia de circulación visibilizó al periódico, sabiendo del tiraje limitado de este impreso y su precio elevado, 20 centavos dólar de la época, representando diez veces más el precio en comparación con los diarios neoyorquinos.

Para influir aún más en la opinión estadounidense, Walker y sus hombres enviaron cientos de ejemplares de El Nicaragüense directamente a redactores de prensa y a políticos en Washington, D.C (Salinas, 1857), y luego negociaron contratos con la empresa distribuidora de prensa Wines and Co. para asegurar la disponibilidad de su publicación en Nueva York, Nueva Orleans y San Francisco (Malè \& Tabor, 1856; Tabor, 1856a). Por medio de esta agencia recibieron también materiales de prensa de Estados Unidos en Granada, generando su propia red de flujos noticiosos, una innovación que antes en Nicaragua no existía. Los redactores nicaragüenses siempre se fiaban en contactos personales para recibir noticias o periódicos para sus propias publicaciones.

En un esfuerzo por ampliar aún más sus esfuerzos propagandísticos, los filibusteros que viajaban a Estados Unidos por motivos de convalecencia o para adquirir material para sus propósitos bélicos en Nicaragua. Muchas veces se presentaban en los diarios estadounidenses como viajeros neutrales,
Según nuestros [nuevos] arreglos estamos preparados para publicar misivas interesantes con cada llegada de correos, con ilustraciones exactas, y como nuestro artistas y reporteros están conectados con el gobierno, podemos ofrecer a nuestros lectores las noticias actuales y fiables ("The Nicaraguan Question, 1856). 
concediendo entrevistas donde falseaban la realidad de la guerra civil inventando supuestas gloriosas victorias.

Otra expresión de simpatía y publicidad hacia la causa mercenaria entre el público norteamericano y ciertos medios de comunicación, se evidencia en la contratación de filibusteros como reporteros para el prestigioso periódico semanal Frank Leslie's Illustrated Newspaper. En abril de 1856, Frank Leslie's anunció:

Según nuestros [nuevos] arreglos estamos preparados para publicar misivas interesantes con cada llegada de correos, con ilustraciones exactas, y como nuestro artistas y reporteros están conectados con el gobierno, podemos ofrecer a nuestros lectores las noticias actuales y fiables ("The Nicaraguan Question, 1856).

A partir del número de abril de 1856 Frank Leslie's (adherente al expansionismo ya desde el inicio de la estancia de Walker) comenzarían a editarse de manera constante, un flujo de imágenes y textos tendenciosos producidos por los filibusteros "corresponsales". Algunas noticias publicadas citaban sus fuentes ("Mr. Douglass E. Jerold" es mencionado como artista), en otras contribuciones la fuente era omitida, desconociéndose quién era el autor del dibujo, ni las razones por las cuales lo hacían.

Las noticias de los supuestos triunfos de los filibusteros únicamente eran publicados por la prensa estadounidense de habla inglesa. Como se ha señalado en este trabajo, el siglo XIX vio nacer en este país, una variedad de publicaciones en español, francés, alemán entre otras lenguas (para la prensa hispanoparlante véase Gruesz, 2002). De estas publicaciones, las escritas en español coincidían con las centroamericanas, en su oposición feroz a la empresa filibustera en Nicaragua. Es verdad que El Nicaragüense en su calidad de órgano oficial del gobierno Walker-Rivas no podía ser ignorado, pero también lo fue que los redactores latinos en Louisiana, lo mismo que Costa Rica o El Salvador, mantuvieron una postura lo suficientemente selectiva y crítica para no caer en el juego de las noticias ficticias fabricadas por los partidarios o simpatizantes de Walker.

Los medios escritos en español refutaron en todo momento las tendenciosas noticias del supuesto éxito militar de los filibusteros, dando espacio en sus páginas a voces opuestas al filibusterismo, como la de José de Marcoleta, embajador nicaragüense en EE UU, cuando Walker llega a Estados Unidos. Con su postura, estos periódicos extendía la oposición centroamericana al filibusterismo hasta la tierra natal del filibustero. Michel Gobat ha argumentado que estas colaboraciones anti-imperialitas a nivel cultural y político, generaron por primera vez una noción de "Latinoamérica", antes de lo que normalmente se reconoce como los inicio de este concepto: la intervención francesa en México en los años 1860 (Gobat, 2013). Sin embargo, la influencia latina se limitaba a los círculos hispanoparlantes en EE UU, reflejando la brecha lingüística encontrada en las propias páginas de El Nicaragüense. Merced de unas pocas traducciones, existió una discusión limitada entre adherentes y oponentes de los filibusteros, pero aún falta un análisis del intercambio textual sobre este tema en la prensa multilingüe estadounidense.

\section{Conclusiones}

El artículo "Introductory" firmado por Malè \& Cook, inaugura el primer número del periódico filibustero en abril de 1856. El texto señalaba:

Con el primer número de El Nicaragüense esperamos que comience una nueva era en la historia de la prensa de Centroamérica. El objetivo de esta publicación será muy diferente de todas las que hasta ahora han aparecido en este Estado. Al mismo tiempo 
su conducta, aunque tal vez no se considere nueva en otros lugares, será completamente nueva acá (Malè \& Cook, 1856).

La intención de los editores del periódico era crear cierta expectativa en la esfera de la prensa periódica y entre los potenciales lectores de habla inglesa, formulando una visión de impacto. Dejando a un lado el tono arrogante de la "proclama", en alguna medida tuvieron razón porque el diseño y las prácticas periodísticas impulsadas eran nuevos en el país centroamericano.

Se podría aceptar que era "diferente" en términos del estilo de periodismo al resto de publicaciones periódicas, vista hasta ese momento en Nicaragua y resto del istmo. No obstante, esta nueva práctica no podía durar mucho, porque no existía el contexto social y político adecuado que lo sustentara. Se carecía de un mercado interno, el segmento letrado era en extremo incipiente (la mayoría de la población era analfabeta), y - el punto más importante - faltaba vinculación con la población nicaragüense.

Aunque algunos colaboradores del periódico como Fermín Ferrer eran nicaragüense, el historiador Michel Gobat argumenta que fueron muy poco los nicaragüenses que participaron en la guerra contra los filibusteros (véase Gobat, 2006, p. 71). Pese a ello, la mayor parte de la élite granadina e incluso de la leonesa, no se identificaron con la publicación filibustera. Considerada de manera correcta como órgano oficial de William Walker (más que de Patricio Rivas), los nicaragüenses evitaron el periódico.

Las proclamas del gobierno de Patricio Rivas no fueron consideradas importantes en el contexto conflictivo de Nicaragua de esa época, menos en Granada, donde se editaba El Nicaragüense. El aislamiento de los editores filibusteros (de ambos idiomas) de la vida cotidiana queda subrayado, entre otros, en el artículo "El Baptismo" fechado en febrero de 1856. Escrito en inglés, a pesar que su título pareciera en español, registra la sorpresa entre los filibusteros al descubrir -cuando escucharon tañer las campanas - las festividades relacionadas con el bautismo de un bebé de la destacada familia Calonje, suceso local de enorme importancia social (Malè \& Cutler, 1856). El hecho que ni los filibusteros cubanos ni anglosajones se enteraran de este evento social evidencia el aislamiento voluntario o impuesto, a que estuvieron sometidos los aventureros norteamericanos durante su estancia en Centroamérica.

No obstante a las ambiciones de sus editores, El Nicaragüense funcionó sólo en dos aspectos: Primero como instrumento propagandístico hacia Estados Unidos. Segundo, como medio oficial de los filibusteros, informando y entreteniendo a la tropa. Esto último, dirige nuestra atención hacia el carácter multinacional de los filibusteros. Aunque la mayoría de ellos provenían y llegaron en barcos de este país del norte, sus filas se vieron engrosadas por migrantes alemanes, húngaros, ingleses y latinoamericanos, principalmente cubanos.

Hasta hoy día es común entre los estudios históricos de los filibusteros ubicarlos como invasores anglosajones. El análisis de El Nicaragüense, a partir de su carácter transnacional, la convergencia de idiomas diferentes, historias y contextos sociales, complejiza esta perspectiva construida a partir de un discurso nacionalista.

Una investigación del periódico filibustero en su "doble cara" (dos idiomas y dos culturas) abre el camino para la comprensión de las razones que motivaron inicialmente la invitación a Nicaragua de los filibusteros; explica por qué contaron con el apoyo de diferentes sectores en América del norte, sur y también de Centroamérica, incluso de Nicaragua: ofrecieron un ideal o visión de progreso social que sedujo a los sectores liberales en todo el hemisferio. Walker y los suyos tenían entonces una narración de 
progreso y modernización que los actores locales de estos países podían vincular con sus intereses.

Los anteriores aspectos encuentran puntos en común entre los filibusteros y liberales nicaragüenses, caudillos locales de diferentes estratos sociales que anhelaban un cambio que rompiera el duopolio entre León y Granada y la creciente centralización del poder (véase Gobat, 2006, p. 77; Kinloch Tijerino, 2006). De igual manera, sugiere que antes de imponer su programa de americanización que amenazara el poder de las elites locales basada en el latifundismo, los filibusteros se inscribían en ejes interpretativos aceptados en Nicaragua.

La publicación El Nicaragüense se ofrece como punto de partida para el análisis de los ejes anteriores -como he señalado-guiando nuestras miradas profesionales hacia actores por mucho tiempo marginados por la personalización de tendencias nacionales y nacionalistas dentro de las diferentes historiografías involucradas en escribir las historias sobre el episodio de los filibusteros en Nicaragua. Algunos colegas de Estados Unidos (como Michel Gobat o Amy Greenberg) o de Costa Rica (Víctor Acuña Ortega) han dedicado sus esfuerzos a esta labor crítica, aunque en Nicaragua faltan iniciativas que superen narrativas estrechas enfocadas en estimular la idea mítica del conjunto nacional forjado en batallas contra las tropas filibusteras.

Si los conceptos "transnacional" o "histoire croisée", actualmente de moda, tienen algún sentido, para mí es este: tratar de pensar y analizar más allá de las fronteras actuales del estado nacional para encontrar y vincular actores, narrativas, objetos y tendencias, sin perderse en alguna idea vaga de lo global. Se trata de identificar objetos concretos de investigación. Un enfoque hacia lo transnacional ayuda no sólo a historiadores e historiadoras para la mejor comprensión de sucesos pasados, sino para promover discusiones necesarias, en conjunto con actores actuales, en función de contribuir a la mejora de las sociedades en que vivimos hoy día.

El modelo de periódico que los filibusteros promovieron con El Nicaragüense fracasó. Después de la victoria de la alianza de los ejércitos centroamericanos, el formato de la nueva Gaceta Oficial que apareció continuó el periodismo oficialista anteriormente conocido en Nicaragua. La Gaceta era un órgano con proclamas destinadas al pequeño círculo de poder y para legitimar sus políticas.

Como la esfera del periodismo está íntimamente vinculada con las económicas y sociales en general, no fue una sorpresa que algo estructuralmente parecido a $E l$ Nicaragüense surgiera nuevamente hasta en la década de 70 de ese siglo XIX, el periódico El Porvenir refleja ecos de esta experiencia. Es un contexto donde los cambios hacia una sociedad más liberal abren nuevos espacios a productores, aumentando la cantidad de consumidores de periódicos. Paradojas de la historiografía, que un precursor de la historia del periodismo centroamericano, pueda encontrarse en esta publicación odiada y menospreciada de los filibusteros.

\section{Referencias bibliográficas}

Agüero Estrada, F. (1856a, abril 5). Los americanos y los Centro-Americanos. El Nicaragüense.

Agüero Estrada, F. (1856b, mayo 16). Dos palabras al pueblo. El Nicaragüense, p. 8.

Anderson, B. R. (2003). Imagined Communities. Reflections on the Origin and Spread of Nationalism. London: Verso.

Ayerdis, M. (2005). Publicaciones Periódicas, Formas de Sociabilidad y Procesos Culturales en Managua (1884-1926). Managua: Banco Central de Nicaragua. Bolaños Geyer, A. (Ed.). (1998). El Nicaragüense, 1855-1856. Edición 
Facsimilar Bilingüe con su Guía = Bilingual Facsimile Edition with a Guide. St. Charles Mo.: A. Bolaños Geyer.

Brodhead, R. H. (1994). Cultures of Letters. Scenes of Reading and Writing in Nineteenth-Century America. Chicago: University of Chicago Press.

Gobat, M. (2006). Reflexiones Sobre el Encuentro Nicaragüense con el Régimen Filibustero de William Waker, 1855-1856. En IHNCA (Ed.), Revista de Historia (pp. 71-89). Managua: Editorial de la UCA.

Gobat, M. (2013). The Invention of Latin America: A Transnational History of Anti-Imperialism, Democracy, and Race. The American Historical Review, (118.5), 1345-1375.

Gruesz, K. S. (2002). Ambassadors of Culture. The Transamerican Origins of Latino Writing. Princeton, Oxford: Princeton University Press.

Guerra, F.-X., \& Lempérière, A. (1998). Los Espacios Públicos en Iberoamérica. Ambigüedades y Problemas; Siglos XVIII - XIX. México, D.F.: Centro Francés de Estudios Mexicanos y Centroamericanos.

Habermas, J. (2010). Strukturwandel der Öffentlichkeit. Untersuchungen zu einer Kategorie der bürgerlichen Gesellschaft; mit einem Vorwort zur Neuauflage 1990 ([12. Aufl.], unveränd. Nachdr. der zuerst 1962 im Luchterhand-Verl. ersch. Ausg., Vol. 891). Frankfurt am Main: Suhrkamp.

Harrison, B. (2004). Agent of Empire. William Walker and the Imperial Self in American Literature. Athens, Ga.: University of Georgia Press.

Kinloch Tijerino, F. (2006). El Primer Encuentro con los Filibusteros: Antecedentes y Contexto. En IHNCA (Ed.), Revista de Historia (Vol. 20,21, pp. 23-45). Managua: Editorial de la UCA.

Lazo, R. (2005). Writing to Cuba. Filibustering and Cuban Exiles in the United States. Chapel Hill, NC: University of North Carolina Press.

Luis-Brown, D. (2009). An 1848 for the Americas. The Black Atlantic, "el
Negro Martir," and Cuban Exile Anticolonialism in New York City. American Literary History, (12.3), 431463.

Malè, J. R., \& Cook, G. (1855, octubre 20). Introductory. El Nicaragüense, p. 1.

Malè, J. R., \& Cutler, C. T. (1856, febrero 2). El Baptismo. El Nicaraguense, p. 2.

Malè, J. R., \& Tabor, J. (1856, agosto 3). New Orleans Papers. El Nicaraguense, p. 1.

May, R. E. (1985). John A. Quitman: Old South Crusader. Baton Rouge: Louisiana State University Press.

Rivas, P. (1856, junio 27). Public Declaration. Rodríguez Díaz, M. (1997). El Destino Manifiesto en el Discurso Político Norteamericano (1776 - 1849). Morelia, Michoacán, México: Universidad Michoacana de San Nicolás de Hidalgo, Instituto de Investigaciones Históricas.

Salinas, S. (1857). Del album semanal de Costa-rica n. 67 copiamos el artículo siguiente: Correspondencia interceptada. Boletín Oficial León, 1(33), 3.

Spurr, D. (2001). The Rhetoric of Empire. Colonial Discourse in Journalism, Travel Writing, and Imperial Administration (5. printing). Durham: Duke University Press.

Streeby, S. (2002). American Sensations. Class, Empire, and the Production of Popular Culture (Vol. 9). Berkeley: University of California Press.

Tabor, J. (1856a). Harper's Magazine/ Late papers. El Nicaraguense, 1(30), 4.

Tabor, J. (1856b). Spanish Editorials. El Nicaraguense, 1(27), 4.

The Nicaraguan Question. (1856). Frank Leslie's Illustrated Newspaper.

Zboray, R. J. (1993). A Fictive People. Antebellum Economic Development and the American Reading Public. New York: Oxford University Press.

Zboray, R. J. (1997). Antebellum Reading and the Ironies of Technological Innovation. En C. N. Davidson (Ed.), Reading in America (pp. 180-200). Baltimore, Md.: Johns Hopkins University Press. 